janko.trupej@gmail.com

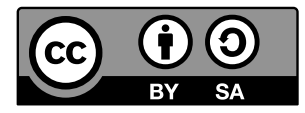

\title{
PREVODOSLOVNA PRIMERJAVA SPREJEMLJIVOSTI PROFANOSTI V SLOVENSKIH, HRVAŠKIH IN SRBSKIH FILMSKIH PODNAPISIH
}

UVOD

Slovenščina je imela izjemno pomembno vlogo pri izoblikovanju slovenske narodne zavesti; Frane Jerman npr. navaja, da je slovenski narod svoj jezik tradicionalno pojmoval kot »simbol svoje nacionalne posebnosti in tudi neodvisnosti« (1993: 13; prim. Menart 1977: 339-40; Bajt 2003: 126), Denis Poniž je slovenski jezik označil za »enega od slovenskih identitetnih stebrov« (2002: 86; prim. Kmecl 2012: 120), Marijan Rupert pa je izjavil, »da sta našo kulturo in državo v veliki meri ustvarjala in konstituirala prav jezik in literatura« (2019). ${ }^{1}$ Zato ne preseneča, da je slovenska literarna kritika tako od izobraženske kot tudi od poljudne literature pričakovala visoko jezikovno raven (Hladnik 1983: 61; prim. Babič 2015: 39); to prav tako velja za slovenske literarne prevode iz različnih obdobij (gl. npr. Čerče 2012: 189; Onič 2013: 249; Trupej 2014b: 102). ${ }^{2}$

Pri slovenskem narodu je sicer precej razširjeno prepričanje, da naj bi bila večina kletvic oz. psovk, ki se uporabljajo v slovenščini, prevzetih iz besedišča drugih južnoslovanskih jezikov; pomanjkanje izvirnih slovenskih kletvic in psovk velja celo za eno izmed prvin, ki slovenščino razločujejo od jezikov vseh drugih narodov nekdanje Jugoslavije, pri katerih naj bi bilo ,nespodobno“ govorjenje občutno bolj sprejemljivo (Fras 2012: 229; prim. Bandur 2016). ${ }^{3}$

1 Majda Stanovnik sicer tudi prevodu pripisuje zelo pomembno vlogo pri konstituiranju slovenskega naroda: »Izoblikoval je prvo različico slovenskega knjižnega jezika in soustvarjal vse nadaljnje, utrjeval je narodno samozavest, izobraževal, odpiral intelektualna obzorja in možnosti za nova duhovna doživetja« (2003: 72).

2 Tudi v drugih kulturah cenzuro oz. samocenzuro profanosti zasledimo tako pri izvirni literarni produkciji (gl. npr. Hughes 1998: 3; Wajnryb 2005: 244; Allan in Burridge 2006: 16) kot pri prevodih - celo kadar gre za kanonizirana besedila (gl. npr. Roterodamus [1518] 2010: 222; d‘Ablancourt [1654] 2010: 250-51; Borges [1935] 2004: 36; Movrin 2010: 109).

3 Kot navaja Ada Vidovič Muha, imajo številni leksemi poleg denotativnega tudi konotativni pomen (2013: 108). Med tovrstne lekseme spadajo tudi prvine profanosti, za katere je lahko značilna inherentna ali adherentna slabšalnost (prav tam: 110-13). Pri psovkah gre npr. za konotativni sinonim denotata, pri kletvicah pa je denotat odsoten. 
$\mathrm{V}$ raziskavi bomo na podlagi korpusne prevodoslovne analize ugotavljali razlike glede sprejemljivosti profanosti ${ }^{4}$ v slovenščini, hrvaščini in srbščini; primerjali bomo pogostost uporabe profanosti pri podnaslovnem prevajanju oz. podnaslavljanju $\mathrm{v}$ te tri jezike. ${ }^{5}$ Za primerjavo filmskih podnapisov smo se odločili, ker povprečen film doseže precej širše občinstvo kot npr. povprečno literarno delo (Rasmussen in Dawidziak 2005: 274-75), zaradi česar utegne biti prekomerna raba profanosti v podnapisih tudi bolj občutljiva problematika. Slednje še v večji meri velja v kulturah, kot so slovenska, hrvaška in srbska, kjer je večina tujih filmov podnaslovljenih in ne sinhroniziranih; ${ }^{6}$ profanost je namreč pojmovana kot bolj nesprejemljiva, kadar se pojavi zapisana na ekranu in ni zgolj izgovorjena (Hjort 2009; prim. Ávila-Cabrera 2015: 53).

Glede uporabe profanosti že dolgo obstajajo številni zadržki: šlo naj bi za verbalno nasilje (Wajnryb 2005: 194), ki izkazuje šibkost (Nežmah 1997: 7; prim. Battistella 2005: 12), pomanjkanje samoobvladovanja, omejen besedni zaklad (Wajnryb 2005: 241) ipd. Vendar so bili v kontekstu filmske oz. literarne produkcije izraženi tudi nekateri drugačni, tj. profanosti bolj naklonjeni pogledi: Ana María Fernández Dobao npr. navaja, da ima profanost pomembno vlogo pri karakterizaciji ${ }^{7}$ filmskih likov (2006: 239), medtem ko Minna Hjort podobno ugotavlja, da raba profanosti sooblikuje družbeno-geografski milje, saj med drugim nakazuje govorčevo starost, raven izobrazbe in družbeni status (2015: 320). Zato bi bilo pomembno profani diskurz ohraniti tudi v podnapisih (Karamitroglou 1997). To pogosto ni povsem izvedljivo, saj za podnaslovno prevajanje veljajo določene časovne in prostorske omejitve, zaradi katerih je včasih treba izpustiti nekatere dele izhodiščnega besedila (Cerar 1995: 58; Kovačič 1995: 62; Carroll in Ivarsson 1998; Bitenc 2003: 77; Zabukovec 2010). ${ }^{8}$ Dobeseden prevod profanosti v mnogih primerih tudi ne bi bil smiseln, saj imajo nekateri izrazi v različnih jezikih sicer enak denotativni pomen, vendar različen konotativni pomen, zato je pri prevajanju priporočljivo uporabljati izraze oz. besedne zveze, ki imajo $\mathrm{v}$ podobnem kontekstu primerljiv ekspresivni pomen in bo njihov učinek torej tudi v ciljni kulturi podoben tistemu v izhodiščni kulturi (Fernández Dobao 2006: 224; prim. Hjort 2015: 323). Uporabljena profanost naj bi v ciljnem jeziku zvenela naravno (Hjort 2009); izziv predstavlja predvsem prevajanje določenih frazemov, pri katerih ustreznice v ciljnem

$4 \quad$ V Slovarju slovenskega knjižnega jezika je pri geslu profán kot razlaga za profano govorjenje navedeno: ,nespodobno, neprimerno‘. Angleška različica tega izraza (profanity) se je sprva navezovala zgolj na bogokletstvo, vendar se je pozneje pomen razširil (Allan in Burridge 2007: 76). Pod okrilje izraza lahko torej prištevamo kletvice, psovke, žaljivke, vulgarizme, blasfemijo, obscenost itd. - v tem smislu je izraz ,profanost " uporabljen tudi v pričujočem članku.

5 Slovenski podnapisi iz korpusa, ki je bil uporabljen za to raziskavo, so bili vključeni že v raziskave o prevajanju profanosti v slovenščino (Trupej 2014a, 2015, 2019); nekateri primeri, ki so bili obravnavani v navedenih prispevkih, so najbolj relevantni tudi pri primerjavi strategij za podnaslovno prevajanje v zadevne tri jezike, zato so vključeni v to razpravo.

6 Za podnaslavljanje filmov se pogosteje odločajo filmski distributerji v manjših državah, medtem ko je v večjih državah bolj razširjena sinhronizacija (Cerar 1995: 58).

7 Za druge prvine, ki vplivajo na karakterizacijo govorcev in govork, gl. Plemenitaš, Friš in Šabeder (2013).

8 Predhodni raziskavi o prevajanju profanosti v slovenščino (Trupej 2015, 2019) sta pokazali, da so pogosto izpuščena predvsem mašila, npr. prislov fucking. 
jeziku ne vsebujejo profanosti. $\mathrm{V}$ takšnih primerih se profanost lahko npr. kompenzira na drugem mestu v besedilu (Fernández Dobao 2006: 228).

Kljub tovrstnim priporočilom glede prevajanja profanosti je bila za filmske oz. televizijske podnapise v številnih jezikih ugotovljena cenzura (gl. npr. Chen 2004; Pujol 2006; Mattsson 2006; Al-Adwan 2015; Mouka, Saridakis in Fotopoulou 2015; Ávila-Cabrera 2016; Trupej 2019). ${ }^{9}$ Pri obravnavanju strategij za izogibanje profanosti pri podnaslovnem prevajanju so bile uporabljene različne kategorizacije premikov $^{10}$ (gl. npr. Bhais 2011; Ghazizadeh in Mardani 2012; Ávila-Cabrera 2015: 40-41, 45). V tem članku bomo uporabljali nekoliko prilagojeno kategorizacijo, ki jo je izoblikovala Kitty van Leuven-Zwart (1990: 72-73, 80-81, 86-87) in smo jo uporabili že za predhodni raziskavi (Trupej 2015, 2019). Poleg primerov, ko je pri prenosu iz izhodiščnega v ciljni jezik profanost ohranjena, je relevantnih šest kategorij premikov: dodajanje, kompenzacija, izpust, radikalna sprememba pomena, modulacija registra in zamenjava $\mathrm{z}$ zaimkom. V nadaljevanju bodo vse omenjene kategorije ponazorjene s pomočjo primerov, nato bodo opredeljene splošne značilnosti strategij za prevajanje profanosti v obravnavanih jezikih. Na podlagi primerov bodo opisane tudi potencialne posledice, ki jih premiki na mikrostrukturni ravni (fraze, stavki in povedi) utegnejo povzročiti na makrostrukturni ravni (gl. van Leuven-Zwart 1989) - spremenijo lahko karakterizacijo, odnose med filmskimi liki ipd. ${ }^{11}$

PREVAJALSKE STRATEGIJE

\section{$2.1 \quad$ Ohranjanje}

V izhodiščnem diskurzu uporabljena profanost ima ustreznico v prevodu.

Primeri:

HRV: $\quad$ What are you doing, asshole? $\rightarrow$ Što radiš, seronjo? (Analyze That / Analiziraj ono $02: 38)^{12}$

SLO: $\quad$ You're fucked. $\rightarrow$ Najebal si. (Constantine / Constantine 23:23)

SRB: A pack of turds dressed in black rode herd on me the whole damn night. $\rightarrow$ Gomila idiota me je jurila celu prokletu noć. (Once Upon a Time in the West / Bilo jednom na Divljem zapadu 58:27)

9 Dušanka Zabukovec, ki je dolga leta vodila prevajalski oddelek na Televiziji Slovenija, je npr. izjavila, da na nacionalni televiziji prevajalcev ne spodbujajo k ohranjanju sleherne nespodobne besede, češ da bi uporaba profanosti gledalce in gledalke zmotila (cit. v Fekonja 2010: 37; gl. tudi Kovačič 1995: 63; Šučur 2015).

10 Premike lahko v prevodoslovnem kontekstu npr. opredelimo kot »spremembe, ki se zgodijo ali se utegnejo zgoditi pri procesu prevajanja« (Bakker, Koster in van Leuven-Zwart 2009: 269) oz. kot »vse, kar se zdi novo glede na izvirnik ali se ne pojavi, kjer bi lahko pričakovali, da se bo« (Popovič 1970; cit. po Bakker, Koster in van Leuven-Zwart 2009: 271).

11 Pri prevodoslovni analizi je s terminom ,mikrostruktura' mišljena besedilna raven, s pojmom ,makrostruktura ‘ pa pripovedna raven.

12 Odebeljen tisk je pri primerih profanosti skozi celotno besedilo dodan za poudarek. 


\section{$2.2 \quad$ Dodajanje}

Profanost se v podnapisih pojavi na mestu, kjer v izhodiščnem diskurzu ni bila uporabljena.

Primeri:

HRV: $\quad$ Harry, you sound trashed. $\rightarrow$ Harry, usrano zvučiš. (Kiss Kiss Bang Bang / Cmok, cmok, bang, bang 49:58)

SLO: If you were a man, you would've done it now! $\rightarrow$ Če bi imel jajca, bi zdaj že opravil. (The Untouchables / Nedotakljivi 66:39)

SRB: $\quad$ Yeah. I'm scared. $\rightarrow$ Da, usrao sam se. (A History of Violence / Istorija nasilja $32: 39)$

\subsection{Kompenzacija}

$\mathrm{V}$ prevodu profanost ni uporabljena na istem mestu kot $\mathrm{v}$ izhodiščnem diskurzu, vendar je kompenzirana drugje. (Pogosto gre za kompenzacijo z drugo besedno vrsto.)

Primeri:

HRV: Of course I can hear what you're fucking saying. $\rightarrow$ Naravno da čujem koja sranja govorite. (Identity / Identitet 67:27)

SLO: I can't believe this is fucking happening! $\rightarrow$ Ne morem verjeti, da se to dogaja, pizda! (A History of Violence / Sence preteklosti 58:01)

SRB: $\quad$ You gotta be fucking kidding me. $\rightarrow$ Mora da me zajebavaš. (A History of Violence / Istorija nasilja 5:32)

\section{$2.4 \quad$ Izpust}

Izvirno uporabljena profanost je v podnapisih izpuščena.

Primeri:

HRV: $\quad$ Enough of this running shit! $\rightarrow$ Dosta je bilo ovog bježanja! (The Untouchables / Nedodirljivi 53:11)

SLO: I'll break your goddamn neck! $\rightarrow$ Polomil vam bom vrat! (Once Upon a Time in America / Bilo je nekoč v Ameriki 15:59)

SRB: How the fuck did you let that happen? $\rightarrow$ Kako si to dozvolio? (Identity / Identitet 03:53) 


\subsection{Modulacija registra}

Denotativni pomen je v podnapisih ohranjen, vendar je uporabljen višji register.

Primeri:

HRV: He fucked his drug counselor's car up. $\rightarrow$ Oštetio je automobil svom savjetniku. (Weather Man / Prognostičar 53:26)

SLO: $\quad$ That motherfucker took his destiny in his own hands. $\rightarrow$ Tip je vzel usodo v svoje roke. (Resurrection / Tupacovo vstajenje 30:27)

SRB: $\quad$ Why protect someone who doesn't give a shit about you? $\rightarrow$ Zašto štitiš nekog ko nimalo ne mari za tebe? ( for Vendetta / V kao vendeta 73:15)

\subsection{Radikalna sprememba pomena}

Pomen izvirnega profanega izraza oz. besedne zveze je v podnapisih radikalno spremenjen.

Primeri:

HRV: $\quad$ Like a ho? $\rightarrow$ Kako? (Borat / Borat 35:18)

SLO: $\quad$ Blow me. $\rightarrow$ Komaj čakam. (Kiss Kiss Bang Bang / Cmok cmok, bang bang 30:21)

SRB: $\quad$ Oh, screw you! $\rightarrow$ Ma daj! (The Man without a Face / Čovek bez lica 12:15)

\subsection{Zamenjava z zaimkom}

Namesto izvirno uporabljene profanosti je v podnapisih uporabljen zaimek.

Primeri:

HRV: $\quad$ Nobody talks to my bitch that way. $\rightarrow$ Nitko tako ne razgovara s njom. (Anger Management / Kontrola besa 12:09)

SLO: $\quad$ I'm rushing the nigga. $\rightarrow$ Napadam ga. (Resurrection / Tupacovo vstajenje 91:08)

SRB: Do you have to go give that old quack your garter? $\rightarrow$ Morala si da mu daš podvezicu? (The Reivers / Lupeži 67:14)

3

\section{ANALIZA KORPUSA}

Analiza je obsegala 20 filmov v skupni dolžini približno 39 ur, ki so izšli pri šestih različnih distributerjih. Analiziran je bil ves izgovorjeni izvirni diskurz, ki vsebuje profanost - vse prevodne rešitve so bile razvrščene v zgoraj navedene kategorije. ${ }^{13}$ Če v izvirniku prisotna profanost ni bila ohranjena zaradi prostorskih in časovnih omejitev oz. če ni bila ohranjena

13 Pri analizi smo naleteli na nekaj pomensko neustreznih prevedkov, vendar tega nismo obravnavali kot premik, če sta bila izraza podobno slogovno zaznamovana. 
niti v izvirnih podnapisih, ki jih prevajalci in prevajalke običajno prejmejo kot referenčni material in se po njih pogosto ravnajo, smo to kategorizirali kot objektivne razloge za to, da profanost ni bila ohranjena, v nasprotnem primeru pa kot (samo)cenzuro. Če je bila izvirna profanost izpuščena, vendar $\mathrm{v}$ istem podnapisu kompenzirana, smo to zabeležili. Rezultati analize so prikazani v spodnji preglednici. ${ }^{14}$

Preglednica 1: Rezultati analize podnaslavljanja profanosti ${ }^{15}$

\begin{tabular}{|c|c|c|c|c|c|c|c|}
\hline \multirow[t]{2}{*}{ Analiziran film } & \multirow[t]{2}{*}{ Jezik } & \multirow{2}{*}{$\begin{array}{l}\text { Profanost je } \\
\text { ohranjena } \\
\text { [dodana] }\end{array}$} & \multicolumn{4}{|c|}{$\begin{array}{l}\text { Profanost ni } \\
\text { ohranjena }\end{array}$} & \multirow{2}{*}{$\begin{array}{l}\text { Cenzura / } \\
\text { objektivni razlogi } \\
\text { [kompenzacija] }\end{array}$} \\
\hline & & & IZP & MR & $\mathbf{Z Z}$ & RSP & \\
\hline \multirow{3}{*}{$\begin{array}{l}\text { A History of } \\
\text { Violence }\end{array}$} & SLO & $46[1]$ & 41 & 12 & 3 & 2 & $53 / 5$ [2] \\
\hline & HRV & $71[0]$ & 27 & 6 & 0 & 0 & $28 / 5$ [3] \\
\hline & SRB & $68[5]$ & 28 & 7 & 0 & 1 & $36 / 0$ [0] \\
\hline \multirow[t]{3}{*}{ Alfie } & SLO & $22[3]$ & 4 & 12 & 0 & 2 & $17 / 1[0]$ \\
\hline & HRV & 29 [3] & 4 & 5 & 0 & 2 & $11 / 0[0]$ \\
\hline & SRB & $28[4]$ & 3 & 5 & 0 & 4 & $11 / 1[0]$ \\
\hline \multirow[t]{3}{*}{ Analyze That } & SLO & $62[3]$ & 114 & 7 & 0 & 3 & 95 / 29 [2] \\
\hline & HRV & $79[5]$ & 90 & 16 & 1 & 0 & 74 / 33 [7] \\
\hline & SRB & $80[6]$ & 88 & 18 & 0 & 0 & 82 / 24 [5] \\
\hline \multirow[t]{3}{*}{ Analyze This } & SLO & $93[3]$ & 56 & 27 & 2 & 1 & $58 / 28$ [2] \\
\hline & HRV & $109[8]$ & 44 & 20 & 0 & 6 & 44 / 26 [9] \\
\hline & SRB & $79[3]$ & 92 & 8 & 0 & 0 & 61 / 39 [0] \\
\hline \multirow{3}{*}{$\begin{array}{l}\text { Anger Manage- } \\
\text { ment }\end{array}$} & SLO & 64 [19] & 19 & 20 & 2 & 3 & 38 / 6 [1] \\
\hline & HRV & $72[18]$ & 16 & 19 & 1 & 0 & 34 / 2 [0] \\
\hline & SRB & 69 [15] & 15 & 23 & 0 & 1 & 37 / 2 [0] \\
\hline \multirow[t]{3}{*}{ Big Fish } & SLO & $12[0]$ & 4 & 10 & 0 & 0 & $13 / 1[0]$ \\
\hline & HRV & $16[1]$ & 3 & 7 & 0 & 0 & 10 / 0 [0] \\
\hline & SRB & $17[2]$ & 4 & 5 & 0 & 0 & $9 / 0[0]$ \\
\hline \multirow[t]{3}{*}{ Borat } & SLO & $55[2]$ & 21 & 3 & 2 & 1 & $24 / 3$ [1] \\
\hline & HRV & 66 [7] & 13 & 2 & 0 & 1 & 13 / 3 [2] \\
\hline & SRB & $67[3]$ & 4 & 10 & 0 & 1 & $15 / 0[0]$ \\
\hline \multirow[t]{3}{*}{ Constantine } & SLO & $22[0]$ & 10 & 3 & 1 & 0 & $13 / 1[0]$ \\
\hline & HRV & $27[0]$ & 6 & 2 & 0 & 1 & $8 / 1[0]$ \\
\hline & SRB & $27[0]$ & 5 & 4 & 0 & 0 & $9 / 0[0]$ \\
\hline
\end{tabular}

14 Preglednice s prevodnimi rešitvami vseh pojavitev profanosti v posameznem filmu so dostopne na naslednjem spletnem naslovu: https://sites.google.com/site/jankotrupej/home/bibliografija/vestnik

15 Kratica IZP označuje izpust, MR modulacijo registra, ZZ zamenjavo z zaimkom in RSP radikalno spremembo pomena. Pri zadnjem stolpcu gre za seštevek vrednosti iz kategorije Profanost ni ohranjena. 


\begin{tabular}{|c|c|c|c|c|c|c|c|}
\hline \multirow[t]{2}{*}{ Analiziran film } & \multirow[t]{2}{*}{ Jezik } & \multirow{2}{*}{$\begin{array}{l}\text { Profanost je } \\
\text { ohranjena } \\
\text { [dodana] }\end{array}$} & \multicolumn{4}{|c|}{$\begin{array}{l}\text { Profanost ni } \\
\text { ohranjena }\end{array}$} & \multirow{2}{*}{$\begin{array}{l}\text { Cenzura / } \\
\text { objektivni razlogi } \\
\text { [kompenzacija] }\end{array}$} \\
\hline & & & IZP & MR & ZZ & RSP & \\
\hline \multirow[t]{3}{*}{ Identity } & SLO & $60[2]$ & 34 & 7 & 0 & 0 & $30 / 11[0]$ \\
\hline & HRV & $73[1]$ & 22 & 6 & 0 & 0 & $14 / 14[6]$ \\
\hline & SRB & $53[2]$ & 39 & 7 & 0 & 2 & $43 / 5[0]$ \\
\hline \multirow{3}{*}{$\begin{array}{l}\text { Kiss Kiss, Bang } \\
\text { Bang }\end{array}$} & SLO & $87[1]$ & 140 & 17 & 3 & 9 & 122 / 47 [5] \\
\hline & HRV & 144 [22] & 96 & 12 & 1 & 3 & 88 / 24 [0] \\
\hline & SRB & 142 [13] & 88 & 21 & 1 & 4 & 86 / 28 [3] \\
\hline \multirow[t]{3}{*}{ Men in Black II } & SLO & $30[6]$ & 14 & 1 & 0 & 0 & $12 / 3[1]$ \\
\hline & HRV & $24[5]$ & 15 & 4 & 1 & 1 & $18 / 3[0]$ \\
\hline & SRB & $31[10]$ & 11 & 3 & 0 & 0 & $11 / 3[0]$ \\
\hline \multirow{3}{*}{$\begin{array}{l}\text { No Direction } \\
\text { Home }\end{array}$} & SLO & $32[3]$ & 9 & 14 & 0 & 0 & 19 / 4 [0] \\
\hline & HRV & $28[2]$ & 13 & 14 & 0 & 0 & $26 / 1[0]$ \\
\hline & SRB & $43[6]$ & 5 & 7 & 0 & 0 & $11 / 1[0]$ \\
\hline \multirow{3}{*}{$\begin{array}{l}\text { Once Upon a } \\
\text { Time in America }\end{array}$} & SLO & $73[2]$ & 51 & 17 & 0 & 3 & $58 / 13$ [0] \\
\hline & HRV & 101 [7] & 26 & 17 & 0 & 0 & 37 / 6 [0] \\
\hline & SRB & $63[3]$ & 47 & 28 & 1 & 5 & $68 / 13[0]$ \\
\hline \multirow{3}{*}{$\begin{array}{l}\text { Once Upon a } \\
\text { Time in the West }\end{array}$} & SLO & $28[1]$ & 2 & 4 & 0 & 1 & $6 / 1[0]$ \\
\hline & HRV & $24[2]$ & 6 & 4 & 1 & 0 & $10 / 1[0]$ \\
\hline & SRB & $24[0]$ & 1 & 9 & 0 & 1 & $10 / 1[0]$ \\
\hline \multirow{3}{*}{$\begin{array}{l}\text { The Man } \\
\text { without a Face }\end{array}$} & SLO & $45[1]$ & 16 & 10 & 0 & 2 & $18 / 10[0]$ \\
\hline & HRV & 64 [3] & 5 & 4 & 0 & 0 & $6 / 3$ [0] \\
\hline & SRB & $63[4]$ & 5 & 4 & 0 & 1 & $8 / 2$ [0] \\
\hline \multirow[t]{3}{*}{ The Reivers } & SLO & $15[6]$ & 10 & 12 & 1 & 0 & $18 / 5$ [0] \\
\hline & HRV & $23[2]$ & 7 & 7 & 1 & 0 & $11 / 4$ [0] \\
\hline & SRB & 23 [1] & 8 & 6 & 1 & 0 & $12 / 3[0]$ \\
\hline \multirow{3}{*}{$\begin{array}{l}\text { The Unotu- } \\
\text { chables }\end{array}$} & SLO & $42[7]$ & 18 & 6 & 0 & 1 & 18 / 7 [0] \\
\hline & HRV & $43[0]$ & 17 & 6 & 1 & 0 & 20 / 4 [1] \\
\hline & SRB & $43[0]$ & 21 & 3 & 0 & 0 & $21 / 3[0]$ \\
\hline \multirow{3}{*}{$\begin{array}{l}\text { The Weather } \\
\text { Man }\end{array}$} & SLO & 96 [3] & 4 & 6 & 0 & 0 & $10 / 0$ [0] \\
\hline & HRV & $96[0]$ & 5 & 5 & 0 & 0 & $9 / 1[0]$ \\
\hline & SRB & $96[0]$ & 5 & 5 & 0 & 0 & $10 / 0$ [0] \\
\hline \multirow{3}{*}{$\begin{array}{l}\text { Tupac: } \\
\text { Resurrection }\end{array}$} & SLO & $47[2]$ & 25 & 23 & 2 & 0 & $38 / 12$ [0] \\
\hline & HRV & $27[5]$ & 54 & 9 & 4 & 3 & $60 / 10[3]$ \\
\hline & SRB & $57[3]$ & 20 & 19 & 0 & 1 & $30 / 10[0]$ \\
\hline
\end{tabular}




\begin{tabular}{|c|c|c|c|c|c|c|c|}
\hline \multirow[t]{2}{*}{ Analiziran film } & \multirow[t]{2}{*}{ Jezik } & \multirow{2}{*}{$\begin{array}{l}\text { Profanost je } \\
\text { ohranjena } \\
\text { [dodana] }\end{array}$} & \multicolumn{4}{|c|}{$\begin{array}{l}\text { Profanost ni } \\
\text { ohranjena }\end{array}$} & \multirow{2}{*}{$\begin{array}{l}\text { Cenzura / } \\
\text { objektivni razlogi } \\
\text { [kompenzacija] }\end{array}$} \\
\hline & & & IZP & MR & $\mathbf{Z Z}$ & RSP & \\
\hline \multirow[t]{3}{*}{$V$ for Vendetta } & SLO & $31[5]$ & 39 & 13 & 1 & 0 & $51 / 2[0]$ \\
\hline & HRV & $58[2]$ & 17 & 8 & 0 & 1 & $26 / 0[0]$ \\
\hline & SRB & $59[8]$ & 11 & 12 & 1 & 1 & $23 / 2$ [0] \\
\hline \multirow[t]{3}{*}{ SKUPAJ } & SLO & $\begin{array}{l}962 \\
(51,7 \%) \\
{[70]}\end{array}$ & $\begin{array}{l}631 \\
(33,9 \\
\%) \\
\end{array}$ & $\begin{array}{l}224 \\
(12,0 \\
\%) \\
\end{array}$ & $\begin{array}{l}17 \\
(0,9 \\
\%) \\
\end{array}$ & $\begin{array}{l}28 \\
(1,5 \\
\%) \\
\end{array}$ & $\begin{array}{l}711(79,0 \%) / \\
189(21,0 \%) \\
{[14]}\end{array}$ \\
\hline & HRV & $\begin{array}{l}1174 \\
(63,1 \%) \\
{[93]}\end{array}$ & $\begin{array}{l}486 \\
(26,1 \\
\%) \\
\end{array}$ & $\begin{array}{l}173 \\
(9,3 \\
\%) \\
\end{array}$ & $\begin{array}{l}11 \\
(0,6 \\
\%) \\
\end{array}$ & $\begin{array}{l}18 \\
(0,9 \\
\%) \\
\end{array}$ & $\begin{array}{l}547(79,5 \%) / \\
141(20,5 \%) \\
{[31]}\end{array}$ \\
\hline & SRB & $\begin{array}{l}1132 \\
(60,8 \%) \\
{[88]}\end{array}$ & $\begin{array}{l}500 \\
(26,9 \\
\%)\end{array}$ & $\begin{array}{l}204 \\
(10,9 \\
\%)\end{array}$ & \begin{tabular}{|l|}
4 \\
$(0,2$ \\
$\%)$
\end{tabular} & $\begin{array}{l}22 \\
(1,2 \\
\%)\end{array}$ & $\begin{array}{l}593(81,2 \%) / \\
137(18,8 \%) \\
{[8]}\end{array}$ \\
\hline
\end{tabular}

V slovenskih podnapisih je bilo ohranjenih $51,7 \%$, v srbskih podnapisih $60,8 \%$ in v hrvaških podnapisih $63,1 \%$ primerov v izhodiščnem diskurzu uporabljene profanosti. Profanost je bila $\mathrm{v}$ slovenskih podnapisih dodana $\mathrm{v} 70$ primerih in kompenzirana $\mathrm{v} 14$ primerih, $\mathrm{v}$ srbskih podnapisih je bila dodana $\mathrm{v} 88$ primerih in kompenzirana $\mathrm{v} 8$ primerih, $\mathrm{v}$ hrvaških podnapisih pa je bila dodana $v 93$ primerih in kompenzirana v 31 primerih. $\mathrm{V}$ primerih, ko profanost ni bila ohranjena, je bil v vseh treh jezikih najpogostejši premik izpust (SLO: 33,9 \%; SRB: 26,9\%; HRV: 26,1 \%), relativno pogosta prevajalska strategija je bila tudi modulacija registra (SLO: 12,0 \%; SRB: 10,9\%; HRV: 9,3 \%), medtem ko so deleži radikalnih sprememb pomena (SLO: 1,5\%; SRB: 1,2 \%; HRV: 0,9 \%) in zamenjav z zaimkom (SLO: 0,9 \%; SRB: 0,2 \%; HRV: 0,6 \%) precej zanemarljivi. V primerih, ko profanost ni bila ohranjena, je delež, ko so za to obstajali objektivni razlogi, v slovenskih podnapisih znašal $21,0 \%$, v srbskih podnapisih $18,8 \%$, v hrvaških podnapisih pa $20,5 \%$.

Za podnapise $\mathrm{v}$ vseh treh jezikih je značilna precejšnja nekonsistentnost pri prevajanju profanih izrazov oz. stalnih besednih zvez, ki se v posameznem filmu pojavijo večkrat. V slovenskih podnapisih je bila npr. radikalno spremenjena protagonistova izjava Can I say 'fuck' more? na začetku filma Kiss Kiss Bang Bang (10:11), ki se navezuje na dejstvo, da je do tistega trenutka šestkrat uporabil izraze s korenom fuck. Ker je v podnapisih le $\mathrm{v}$ enem primeru uporabljena primerljivo vulgarna prevodna rešitev, se prevod omenjene izjave glasi Preklinjati pa znam, ja. V srbskih podnapisih je vulgarnost izraza ohranjena v štirih primerih in izjava je prevedena kot Mogu li još da govorim 'jebi ga'. Prav toliko pojavitev izraza je ohranjenih v hrvaških podnapisih, kjer se prevod izjave glasi Smijem li još reći 'jebeno'? Eksplicitno na izraz fuck se navezuje tudi izjava na koncu tega filma (95:05): For all of you good people in the Midwest, sorry we said 'fuck' so much. V slovenskih podnapisih tudi tokrat zasledimo enako radikalno spremembo pomena kot prej: $[V]$ sem zadrtežem pa se oproščam, ker smo preklinjali. V srbskih podnapisih 
je bila zaradi pogostih premikov pri prevajanju zadevnega izraza prav tako uporabljena tovrstna prevodna rešitev: [Z] a sve vas dobre ljude sa Srednjega zapada, izvinite zbog psovanja. Le v hrvaščini se tudi tokrat izjava dejansko navezuje na specifičen termin: $Z a$ sve vas, dobre ljude iz Midwesta, oprostite što smo toliko puta rekli 'jebi ga'.

Dodajanje profanosti je razmeroma pogosto v vseh treh jezikih, kar utegne včasih celo spremeniti pomen diskurza. Kot primer navajamo naslednjo izjavo iz filma Men in Black II (36:15): My business is banging, dog. Izraz bang sicer ima vulgarno konotacijo, kadar je uporabljen za spolno občevanje, vendar tokrat ne gre za to. Prav tako je izraz dog lahko žaljivka, če je nekdo verbalno degradiran na živalsko raven, toda v tem primeru gre dejansko za izražanje naklonjenosti do sogovornika. Slednje je v slovenskem prevodu ohranjeno: Posel cveti, stari. V hrvaškem prevodu zasledimo izpust zadnje besede v povedi: Posao dobro ide. $\mathrm{V}$ srbskih podnapisih pa zasledimo dva primera dodane profanosti: Posao mi ide do jaja, psu. Dobesedni prevod izraza dog dejansko predstavlja radikalno spremembo pomena, saj imata oba izraza enak denotativni pomen, vendar v dotičnem primeru različen konotativni pomen - v srbskih podnapisih je izjava žaljiva do naslovnika.

Predvsem v hrvaških podnapisih je profanost pogosto kompenzirana. Stalna besedna Shut the fuck up!, ki jo eden od likov v filmu Analyze This dvakrat naslovi na isto osebo (6:29; 8:15), je v hrvaških podnapisih v obeh primerih prevedena kot Zaveži, jebi ga!, medtem ko je v srbskih podnapisih najprej prevedena kot Zaveži već jednom!, nato pa $\mathrm{v}$ Zaveži!, torej gre za dve modulaciji registra. V slovenskih podnapisih je izjava prvič prevedena kot Utihni!, kar prav tako predstavlja modulacijo registra, drugič pa v Zapri gobec!. Nadaljnji nazoren primer, kako je bila profanost na izvirnem mestu izpuščena, toda nato kompenzirana drugje, je izjava You fuck the shit out of them! iz filma Borat (59:38). Srbski prevod se glasi Jebeš ih dok se ne useru!; torej je uporabljena tudi ustreznica za izraz shit - v izvirniku gre sicer za samostalnik, v prevodu pa za glagol. Kompenzacijo zasledimo tudi v hrvaškem prevodu, ki se glasi Izjebeš ih kao krave!. Slovenski podnapis se glasi Pofukaš jih[.] - prevedka za izraz shit torej ni. Tudi nasploh velja, da so stalne besedne zveze, ki vsebujejo profanost, v slovenščini pogosteje kot v srbščini ali hrvaščini prevedene nevtralno - npr. naslednja iz filma Alfie (11:38): We have something here, or am I just a glorified booty call?. Slovenski prevod se glasi Je med nama nekaj resnega ali sem samo zlata rezerva?, hrvaški Imamo li mi što, ili sam ja cijenjeni poziv za ševu?, srbski pa Da li među nama ima nečega, ili sam samo počasna faćkalica?.

Pogosto so različni pristopi uporabljeni v primerih, ko bi bilo treba spremeniti denotativni pomen izvirnega diskurza, da bi se v ciljnem besedilu ohranil konotativni pomen. Nazoren primer je naslednja izjava iz filma Anger Management (35:56): Might I have your first name, Mr. Head? And tell me it isn't Dick. V hrvaških podnapisih se prevod glasi: Kako vam je ime, g. Glava? Nije valjda Kurčeva?. Ime in priimek te osebe sta torej prevedena, s čimer je ohranjena tudi žalitev. Tega ni mogoče trditi za slovenske in srbske podnapise, kjer se prevoda glasita Mi zaupate svoje ime, g. Head? Menda ni Dick. oz. Možete li mi reći svoje ime, g. Hed? Samo da nije Dik. Podoben primer v istem filmu zasledimo, ko protagonist vstopi v restavracijo v družbi dveh spremljevalk z globokim 
dekoltejem, nakar jih natakar vpraša: Would you like a boobs—? Booth? (73:47). Hrvaški prevod se glasi Želite li sisa... Separe?, srbski Želite li sisare ... separe?, slovenski pa Bi se parili ... Bi separe?. V hrvaških in srbskih podnapisih je profanost sicer ohranjena, $\mathrm{v}$ slovenski različici pa ne, vendar $\mathrm{v}$ tem primeru za to obstajajo objektivni razlogi, saj je bil cilj doseganje blizuzvočja - torej tega ne gre obravnavati kot (samo)cenzuro.

Izziv predstavlja tudi prevajanje kulturno specifične profanosti. Trije različni pristopi so npr. uporabljeni za podnaslavljanje naslednje razlage o razliki med izrazoma nigga in nigger v filmu Tupac: Resurrection (73:04): Niggas. He's talking about niggers. Niggers was the ones on the rope, hanging off the thing. Niggas is the ones with gold ropes, hanging out at clubs. V slovenskih podnapisih je za oba angleška izraza uporabljen isti izraz: On je govoril o drugačnih črnuhih. Njegovi črnuhi so tisti, ki visijo z vrvi. Moji črnuhi pa imajo zlate vrvi in visijo po klubih. ${ }^{16} \mathrm{~V}$ hrvaških podnapisih najprej zasledimo negativno zaznamovan hrvaški izraz, nato pa sta prevzeta angleška izraza: Ja spominjem svoju braću, a oni crnčuge. 'Nigg-ers' su oni koje su vješali po stablima. 'Nigg-as' su oni sa zlatnima lancima, koji vise po klubovima. V srbskih podnapisih pa sta uporabljena dva različna negativno zaznamovana srbska izraza: 'Cr-nje.' On govori o 'crn-čugama'. 'Crn-čuge' su bili oni na konopcu, što su visili. 'Cr-nje' su oni sa zlatnim konopcima, koji vise po klubovima. ${ }^{17}$

VPLIV PREMIKOV NA MAKROSTRUKTURNO RAVEN

V filmu Analyze That policijski načelnik v odzivu na poskus ropa konvoja, ki prevaža zlate palice, $\mathrm{v}$ manj kot minuti uporabi šest primerov profanosti, kar je $\mathrm{v}$ podnapisih $\mathrm{v}$ treh obravnavanih jezikih ohranjeno $\mathrm{v}$ različni meri:

ANG: Are you fucking kidding me? /.../ We're gonna back these fuckers out of here. What the fuck? /.../ They're lifting the fucking truck! Son of a bitch! /.../You have got to be fucking kidding me!

SLO: To ni res! /.../ Vzvratno gremo. /.../ Dvigujejo kamion! /.../ To ni res!

HRV: Zajebavate me? /.../ Izaći ćemo unatrag. Koji kurac? /.../ Dižu kamion! Pas mater! /.../ Ma zajebavate me!

SRB: Da li me ti to zajebavaš? /.../ Vratićemo ove budale odavde. Šta je to [sic] jebote? /.../ Podižu kamion! Kučkin sin! /.../ Mora da se šalite! (73:52)

16 Ena od potencialnih prevodnih rešitev bi bila uporabiti dva različno zaznamovana negativna slovenska izraza za temnopolte. Za primerjavo slogovne zaznamovanosti najpogostejših slovenskih terminov za temnopolte gl. Trupej (2014c: 639-42).

17 Podobno kot je bilo ugotovljeno za slovenske literarne prevode (gl. npr. Trupej 2014b, 2017a), negativno zaznamovani rasni izrazi tudi v filmskih podnapisih pogosto niso bili ohranjeni. V filmu The Reivers se npr. izraz nigger pojavi štirikrat in medtem ko je $\mathrm{v}$ hrvaščini trikrat ohranjena negativna konotacija tega izraza, to za srbščino in slovenščino velja le $\mathrm{v}$ enem primeru. 
Medtem ko je v hrvaščini in srbščini profanost ohranjena v štirih primerih, je v slovenščini povsem cenzurirana, pri čemer sta dve vrstici podnapisov popolnoma izpuščeni, ne da bi bilo to potrebno zaradi prostorskih oz. časovnih omejitev. Slovenski gledalci torej slišijo govorjeni diskurz, vendar ne vidijo podnapisov, kar jih utegne zmotiti (gl. Hjort 2009). V tem primeru to sicer nima bistvenega vpliva na makrostrukturno raven filma. V večji meri na makrostrukturo vpliva cenzura profanosti v filmu Analyze This, predvsem pri diskurzu protagonista Paula Vittija - mafijskega šefa, ki se npr. na poskus umora odzove z naslednjimi besedami:

ANG: You make one more move on me, you motherfucker, I'll fucking cut your fucking balls off! I'll shove them up your fucking ass, I'll fucking bury you! I'll put fucking ice picks in your eyes! I'll chop your fucking eyeballs! I'll send them to your fucking family to eat for dessert! /.../ You motherfucker!

SLO: $\quad$ Če boš še kaj poskušal, ti bom odrezal jajca! Nato ti jih bom zatlačil v rit. In te pokopal! V oči ti bom zabil cepina! Razsekal ti bom zrkli! Poslal jih bom tvoji družini, da jih bodo imeli za poobedek! /.../ Ti pofukanec!

HRV: Napadneš li me opet, jebem ti mater, odrezat ću ti jebena jaja! I strpati u jebenu guzicu! I pokopati te, jebi ga! Jebenim šiljcima za led probušit ću ti oči i narezuckati jebene očne jabučice! I poslati ih tvojoj jebenoj obitelji da pojede [sic] za desert! /.../ Jebem ti mater!

SRB: $\quad$ Ako još jednom kreneš na mene otkinuću ti muda i nabiti ih u dupe! Zakopaću te! Zabiću ti šiljke za led u oči! Iskopaću ti jabučice! Poslaću ih tvojoj porodici da ih pojedu za dezert! /.../ Drkadžijo! (47:10)

Od enajstih primerov profanosti v izvirniku jih je v hrvaških podnapisih ohranjenih deset, v slovenskih in srbskih pa le tri oz. dva. To bistveno spremeni raven agresivnosti zgornjega izbruha. Ker v slovenskih in srbskih podnapisih profanost skozi celoten film pogosto ni ohranjena, je karakterizacija tega lika bistveno spremenjena: deluje bolj omikano in manj agresivno. Ávila-Cabrera trdi, da raba profanosti ni le pomemben del karakterizacije, temveč prispeva tudi k razumevanju dogajanja (2015: 42), kar velja predvsem za situacije, ko verbalno nasilje privede do fizičnega nasilja (Nežmah 1997: 81; prim. Hughes 1998: 6; Wajnryb 2005: 143). Nazoren primer, kako lahko izogibanje profanosti v podnapisih neposredno vpliva na razumevanje dogajanja, zasledimo v filmu $A$ History of Violence, ko srednješolec $\mathrm{z}$ naslednjimi besedami nagovori protagonista in njegovo prijateljico:

ANG: So, your old man's some kind of tough guy, huh? What's he think of his wimp son? You think he'd take this shit? You think he'd make jokes? Go on, bitch. Say something funny. /.../ Shut up, skank. /.../ Yeah, puss. Run away. Goddamn, I bet your daddy would be real ashamed by you. Go ahead, bitch. Say something funny. 
SLO: $\quad$ Tvoj stari je pravi silak, kaj? Kaj pravi na mevžastega sina? Bi prenašal tvoje duhovičenje? Povej kaj duhovitega. /.../ Tiho, kuzla. /.../ Ti kar stisni rep med noge. Tvoj oče bi se te sramoval. Povej kaj duhovitega[.]

HRV: Stari ti je opasan tip? Što misli o sinu mlakonji? Trpio bi ovo sa smiješkom? Reci nešto smiješno, pičko. /.../ Zašuti, droljo. /.../ Da, pičkice. Samo pobjegni. Kladim se da bi te se tata sramio. Reci nešto smiješno, kučko.

SRB: Znači, tvoj matori je neki opasan tip? Šta misli o svom pičkastom sinu? Misliš da bi on trpeo ova sranja i zezao se? Hajde, pičko, reci nešto smešno. /.../ Umukni, droljo. /.../ Da, pičko, beži. Majku mu, tvog ćaleta bi sigurno bila sramota od tebe. Hajde, pičko, reci nešto smešno. (46:24)

Razžaljeni protagonist se na to odzove tako, da sošolca brutalno pretepe. V srbščini je ohranjenih vseh sedem primerov izvirne profanosti, v hrvaščini pet, v slovenščini pa je profanost ohranjena le dvakrat, kar lahko vpliva na to, kako občinstvo dojema ta diskurz - marsikomu se tako nasilen odziv utegne zdeti bistveno manj razumljiv, kot če bi bili ohranjeni vsi žaljivi izrazi.

\section{5}

\section{ZAKLJUČEK}

Analiza 20 filmov, podnaslovjenih v slovenščino, hrvaščino in srbščino, je pokazala številne skupne značilnosti, pa tudi nekatere razlike. Iz seznamov vseh prevodnih rešitev za uporabljeno profanost v posameznem filmu je razvidno, da so bile v primerih, ko je bila profanost ohranjena, v vseh treh jezikih za isti izraz oz. frazo pogosto uporabljene različne prevodne rešitve. $\mathrm{V}$ slovenskih podnapisih je bila skupno ohranjena dobra polovica profanosti, v hrvaških in srbskih podnapisih pa nekaj več kot $60 \%$. V vseh treh jezikih smo pri približno petini vseh neohranjenih primerov ugotovili objektivne razloge, medtem ko lahko ostale primere obravnavamo kot (samo)cenzuro. Podrobnejša kategorizacija primerov, pri katerih profanost ni bila ohranjena, je pokazala, da je bila v slovenskih podnapisih izpuščena občutno bolj pogosto kot v hrvaških in srbskih podnapisih, medtem ko razlike $\mathrm{v}$ deležih modulacij registra, radikalnih sprememb pomena in zamenjav z zaimkom niso tolikšne. Profanost je bila v slovenskih podnapisih dodana nekoliko redkeje kot v srbskih in hrvaških podnapisih, v slednjih podnapisih pa je bila tudi občutno najpogosteje kompenzirana. Različne prevajalske pristope smo ponazorili tudi z nekaterimi primeri in pojasnili smo, kako lahko uporabljene strategije za prevajanje profanosti vplivajo na mikrostrukturo oz. makrostrukturo filmov, npr. na razumevanje dogajanja, karakterizacijo in percepcijo odnosov med filmskimi liki.

Glede na rezultate analize lahko sklepamo, da je za prevajalce in prevajalke ohranjanje profanosti pri prevajanju v slovenščino nekoliko manj sprejemljivo kot pri prevajanju v hrvaščino ali srbščino, vendar so razlike manjše, kot bi morda pričakovali - izjemoma 
je profanost v slovenskih podnapisih ohranjena celo v večji meri kot v srbskih oz. hrvaških podnapisih. ${ }^{18}$ Morda lahko prepričanje, da je uporaba profanosti v hrvaščini oz. srbščini veliko bolj sprejemljiva kot v slovenščini, torej razumemo v kontekstu splošne slovenske težnje po distanciranju od drugih južnoslovanskih narodov (Žižek 2000: 601; prim. Udovič in Bučar 2016: 1064-66). Za celovitejšo primerjavo sprejemljivosti profanosti v posamezni obravnavani kulturi bi bile sicer potrebne nadaljnje - zlasti korpusno podprte - primerjalne analize uporabe profanosti v različnih vrstah diskurza.

Pričujoča raziskava prevajalcem in prevajalkam utegne koristiti pri odločanju glede strategij za prevajanje profanosti, prav tako pa je lahko izhodišče za nadaljnje raziskave o sprejemljivosti profanosti pri podnaslovnem prevajanju, $\mathrm{v}$ katere bi bilo poleg prevajalcev in prevajalk smiselno vključiti tudi druge deležnike, npr. urednike in urednice pri televizijskih hišah, distributerje ter nenazadnje gledalce in gledalke.

\section{ANALIZIRANI FILMI}

A History of Violence / Povijest nasilja / Sence preteklosti / Istorija nasilja. Režija: David Cronenberg. 2005. Ljubljana: JA-MI, 2006. DVD.

Alfie / Alfie / Alfie / Alfi. Režija: Charles Shyer. 2004. Ljubljana: Karantanija cinemas, 2005. DVD.

Analyze That / Analiziraj ono / Mafijski blues / Mafijaš pod stresom. Režija: Harold Ramis. 2002. Ljubljana: Art vidis, 2003. DVD.

Analyze This / Analiziraj ovo / Analiza pa taka / Mafijaš na terapiji. Režija: Harold Ramis. 1999. Ljubljana: Con film, 2006. DVD.

Anger Management / Kontrola besa / Bes pod kontrolo / Bez ljutnje, molim. Režija: Peter Segal. 2003. Škofljica: Blitz film, 2003. DVD.

Big Fish / Krupna riba / Velika riba / Krupna riba. Režija: Tim Burton. 2003. Škofljica: Blitz film, 2004. DVD.

Borat: Cultural Learnings of America for Make Benefit Glorious Nation of Kazakhstan / Borat: Učenje o amerika kultura za boljitak veličanstveno država Kazahstan / Borat: Učenje o američka kultura za krasna narod Kazahstanski / Borat. Režija: Larry Charles. 2006. Ljubljana: Con film, 2006. DVD.

Constantine / Constantine / Constantine / Konstantin. Režija: Francis Lawrence. 2005. Ljubljana: JA-MI, 2005. DVD.

Identity / Identitet / Identiteta / Identitet. Režija: James Mangold. 2003. Škofljica: Blitz film, 2006. DVD.

Kiss Kiss Bang Bang / Cmok, cmok, bang, bang / Cmok cmok, bang bang / Kis kis, beng beng. Režija: Shane Black. 2005. Ljubljana: JA-MI, 2006. DVD.

18 Podobno smo ugotovili tudi pri primerjavi prevajanja negativnih poimenovanj za temnopolte $\mathrm{v}$ slovenskem in srbo-hrvaškem prevodu istega književnega dela (gl. Trupej 2017b: 132). 
Men in Black II / Ljudi u crnom 2 / Možje v črnem II / Ljudi u crnom 2. Režija: Barry Sonnenfeld. 2002. Škofljica: Blitz film, 2002. DVD.

No Direction Home / Bob Dylan: Bez povratka kući / Brez poti domov: Bob Dylan / Bob Dilan: Nema puta kući. Režija: Martin Scorsese. 2005. Ljubljana: Karantanija cinemas, 2005. DVD.

Once Upon a Time in America / Bilo jednom u Americi / Bilo je nekoč v Ameriki / Bilo jednom u Americi. Režija: Sergio Leone. 1984. Ljubljana: JA-MI, 2003. DVD.

Once Upon a Time in the West / Bilo jednom na Divljem zapadu / Bilo je nekoč na Divjem zahodu / Bilo jednom na Divljem zapadu. Režija: Sergio Leone. 1968. Los Angeles: Paramount Pictures, 2003. DVD.

The Man Without a Face / Čovjek bez lica / Mož brez obraza / Čovek bez lica. Režija: Mel Gibson. 1993. Škofljica: Blitz film, 2004. DVD.

The Reivers / Lopovi / Tatovi / Lupeži. Režija: Mark Rydell. 1969. Ljubljana: Karantanija cinemas, 2006. DVD.

The Untouchables / Nedodirljivi / Nedotakljivi / Nesalomivi. Režija: Brian De Palma. 1987. Ljubljana: Karantanija cinemas, 2004. DVD.

The Weather Man / Prognostičar / Vremenar / Najavljivač vremena. Režija: Gore Verbinski. 2005. Ljubljana: Karantanija cinemas, 2006. DVD.

Tupac: Resurrection / Tupac: Uskrsnuće / Tupacovo vstajenje / Tupakovo uskrsnuće.

Režija: Lauren Lazin. 2003. Ljubljana: Karantanija cinemas, 2004. DVD.

$V$ for Vendetta / O za osvetu / V kot vroče maščevanje / V kao vendeta. Režija: James McTeigue. 2005. Ljubljana: JA-MI, 2006. DVD.

\section{BIBLIOGRAFIJA}

AL-ADWAN, Amer Samed (2015) Towards a Model of Euphemisation in Arabic Subtitling. Arab World English Journal Special Issue on Translation 4, 6-21. <http:// www.awej.org/images/AllIssues/Specialissues/Translation4/1.pdf>. (Dostop 6. 2. 2020.)

ALLAN, Keith/Kate BURRIDGE (2007) Forbidden Words: Taboo and the Censoring of Language. Cambridge: Cambridge University Press.

ÁVILA-CABRERA, José Javier (2015) An Account of the Subtitling of Offensive and Taboo Language in Tarantino's Screenplays. Sendebar: Revista de la Facultad de Traducción e Interpretación 26, 37-56. < http://revistaseug.ugr.es/index.php/sendebar/article/viewFile/2501/3789>. (Dostop 6. 2. 2020.)

ÁVILA-CABRERA, José Javier (2016) The Subtitling of Offensive and Taboo Language into Spanish of Inglourious Basterds. Babel 62 (2), 211-232.

BABIČ, Saša (2015) Beseda ni konj: Estetska struktura slovenskih folklornih obrazcev. Ljubljana: Založba ZRC, ZRC SAZU. 
BAJT, Drago (2003) Nič je premalo, malo je preveč. Avtorski honorarji za književna dela v povojnem obdobju (1945-2003). Martina Ožbot in Matej Hriberšek (ur.), Nesem te v zibel drugega jezika. Zbornik ob petdesetletnici društva. Ljubljana: Društvo slovenskih književnih prevajalcev, 113-144.

BAKKER, Matthijs/Cees KOSTER/Kitty VAN LEUVEN-ZWART (2009) Shifts. Mona Baker in Gabriela Saldanha (ur.), Routledge Encyclopedia of Translation Studies (2nd Edition). London/New York: Routledge, 269-274.

BANDUR, Simona (2016) Dokler bo spolnost tabu, bo nastopala v kletvicah. Delo, 1. junij. <http://www.delo.si/prosti-cas/zanimivosti/dokler-bo-spolnost-tabu-bo-nastopala-v-kletvicah.html>. (Dostop 6. 2. 2020.)

BATTISTELLA, Edwin L. (2005) Bad Language: Are Some Words Better Than Others? New York: Oxford University Press.

BHAIS, Eid Mohammad (2011) The Translatability of English Profanity in Arabic Subtitles: diplomsko delo. Palestina: Hebron University. <http://www.cjc-online.ca/index.php/journal/thesis/view/137>. (Dostop 6. 2. 2020.)

BITENC, Ani (2003) Misli in spomini ob 50-letnici društva. Martina Ožbot in Matej Hriberšek (ur.), Nesem te v zibel drugega jezika. Zbornik ob petdesetletnici društva. Ljubljana: Društvo slovenskih književnih prevajalcev, 76-78.

BORGES, Jorge Luis ([1935] 2004) The Translators of the Thousand and One Nights. Lawrence Venuti (ur.), Translation Studies Reader. London: Routledge, 34-48. Prev. Esther Allen.

CARROLL, Mary/Jan IVARSSON (1998) Code of Good Subtitling Practice. ESIST. $<$ http://www.esist.org/wp-content/uploads/2016/06/Code-of-Good-Subtitling-Practice.PDF.pdf>. (Dostop 6. 2. 2020.)

CERAR, Vasja (1995) Prevod kot del filmskega teksta. Majda Stanovnik (ur.), Prevajanje slovenske književnosti. Prevajanje za kino in RTV. Ljubljana: Društvo slovenskih književnih prevajalcev, 56-59.

CHEN, Chapman (2004) On the Hong Kong Chinese Subtitling of English Swearwords. Meta: journal des traducteurs / Meta: Translators' Journal 49 (1), 135-147. <http:// www.erudit.org/revue/meta/2004/v49/n1/009029ar.pdf $>$. (Dostop 6. 2. 2020.)

ČERČE, Danica (2012) (Ne)prevedljivost pogovornega jezika v delih Johna Steinbecka. Slavistična revija 60 (2), 185-198. <http://www.srl.si/sql_pdf/SRL_2012_2_04. pdf>. (Dostop 6. 2. 2020.)

D’ABLANCOURT, Nicolas Perrot ([1654] 2010) Posvetilo k nezvesti lepotici. David Movrin, Fidus interpres = Zvest prevajalec: slike iz dveh tisočletij zgodovine prevajanja. Ljubljana: Založba ZRC, ZRC SAZU/Znanstvena založba FF (Zbirka Studia translatoria, 2), 247-253. Prev. David Movrin.

FEKONJA, Katarina (2010) Trainspotting: primerjava prevodov preklinjanja v literarnem delu in filmskih podnapisih: diplomsko delo. Maribor: Filozofska fakulteta. 
FERNÁNDEZ DOBAO, Ana María (2006) Linguistic and Cultural Aspects of the Translation of Swearing: The Spanish Version of Pulp Fiction. Babel 52 (3), 222-242.

FRAS, Jona (2012) The Ideology of Swearwords in Slovenia. Language \& Communication 32 (3), 229-239.

GHAZIZADEH, Khalil/Vahid MARDANI (2012) An Investigation of Translator's Strategies in Translating Western Taboos in Dubbing English-Language Movies into Persian. Language and Translation Studies 45 (1), 85-99.

HJORT, Minna (2009) Swearwords in Subtitles: A Balancing Act. Michela Giorgio Marrano, Giovanni Nadiani in Christopher Rundle (ur.), inTRAlinea Special Issue: The Translation of Dialects in Multimedia. <http://www.intralinea.org/specials/article/ Swearwords in Subtitles>. (Dostop 6. 2. 2020.)

HJORT, Minna (2015) Vittu and Fuck - Tales from a Literary Coexistence. Ulla Tuomarla et al. (ur.), Miscommunication and Verbal Violence / Du malentendu à la violence verbale / Misskommunikation und verbale Gewalt. Helsinki: Société Néophilologique, 319-330. <https://tuhat.halvi.helsinki.fi/portal/files/49995712/Dialog3_painoon.pdf\#page $=333>$. (Dostop 6. 2. 2020.)

HLADNIK, Miran (1983) Trivialna literatura. Ljubljana: DZS.

HUGHES, Geoffrey (1998) Swearing: A Social History of Foul Language, Oaths and Profanity in English. London: Penguin.

JERMAN, Frane (1993) Književni prevod in nacionalna identiteta. Majda Stanovnik (ur.), Prevod in narodova identiteta. Prevajanje poezije. Ljubljana: Društvo slovenskih književnih prevajalcev, 11-14.

KARAMITROGLOU, Fotios (1997) A Proposed Set of Subtitling Standards in Europe. European Association for Studies in Screen Translation. <http://www.sub2learn.ie/ downloads/karamitroglou_fotiosa_proposed_set_of_subtitling_standards_in_europe.pdf $>$. (Dostop 6. 2. 2020.)

KMECL, Matjaž (2012) Po zgodovinski naravi stvari smo Slovenci vsi po vrsti »obsojeni« na nenehno tuhtanje svoje usode. Literatura 250, 119-136.

KOVAČIČ, Irena (1995) Jezik televizijskih podnapisov. Majda Stanovnik (ur.), Prevajanje slovenske književnosti. Prevajanje za kino in RTV. Ljubljana: Društvo slovenskih književnih prevajalcev, 59-68.

MATTSSON, Jenny (2006) Linguistic Variation in Subtitling: The Subtitling of Swearwords and Discourse Markers on Public Television, Commercial Television and DVD. Mary Carroll, Heidrun Gerzymisch-Arbogast in Sandra Nauert (ur.), MuTra 2006 - Audiovisual Translation Scenarios: Conference Proceedings. Saarbrücken: Saarland University, 47-56.

MENART, Janez (1977) Tudi jezik je politika. Sodobnost 25 (4), 337-341.

MOUKA, Effie/Ioannis E. SARIDAKIS/Angeliki FOTOPOULOU (2015) Racism Goes to the Movies: A Corpus-Driven Study of Cross-Linguistic Racist Discourse 
Annotation and Translation Analysis. Claudio Fantinuoli in Federico Zanettin (ur.), New Directions in Corpus-based Translation Studies (Translation and Multilingual Natural Language Processing 1). Berlin: Language Science Press, 35-69.

MOVRIN, David (2010) Fidus interpres = Zvest prevajalec: slike iz dveh tisočletij zgodovine prevajanja. Ljubljana: Založba ZRC, ZRC SAZU/Znanstvena založba FF.

NEŽMAH, Bernard (1997) Kletvice in psovke. Ljubljana: Nova revija.

ONIČ, Tomaž (2013) Vikanje in tikanje v slovenskih prevodih Albeejeve drame Kdo se boji Virginie Woolf?. Primerjalna književnost 36 (1), 233-252. <http://www.dlib.si/ details/URN:NBN:SI:DOC-BUK8UJAO>. (Dostop 6. 2. 2020.)

PLEMENITA ̌́, Katja/Eva Lina FRIŠ/Nik ŠABEDER (2013) The Art of Words in British Politics in the 20 ${ }^{\text {th }}$ Century: Chamberlain's and Churchill's Use of Language: A Comparative Analysis. Studia Historica Slovenica 13 (1), 265-290.

PONIŽ, Denis (2002) 1920-1929. Denis Poniž (ur.), Beseda se vzdiguje v dim: stoletje slovenske lirike 1900-2000. Ljubljana: Cankarjeva založba, 75-99.

PUJOL, Dídac (2006) The Translation and Dubbing of 'Fuck' into Catalan: The Case of From Dusk till Dawn. The Journal of Specialised Translation 6, 121-133.

RASMUSSEN, R. Kent/Mark DAWIDZIAK (2005) Mark Twain on the Screen. Peter Messent in Louis J. Budd (ur.), A Companion to Mark Twain. Malden: Blackwell Publishing, 274-289.

ROTERODAMUS, Desiderius Erasmus ([1518] 2010) Pismo o prevajanju Nove zaveze. David Movrin, Fidus interpres = Zvest prevajalec: slike iz dveh tisočletij zgodovine prevajanja. Ljubljana: Založba ZRC, ZRC SAZU/Znanstvena založba FF (Zbirka Studia translatoria, 2), 221-245. Prev. David Movrin.

RUPERT, Marijan (2019) Našo kulturo in državo sta ustvarjala in konstituirala jezik in literatura. Odkrito.si, 26. maj. <https://odkrito.svet24.si/clanek/zivljenjskislog/ naso-kulturo-in-drzavo-sta-ustvarjala-in-konstituirala-jezik-in-literatura-704233>. (Dostop 6. 2. 2020.)

STANOVNIK, Majda (2003) Zimzeleno vprašanje Otona Župančiča: Od kod in kam te nesejo peroti po jasni zračni poti?. Martina Ožbot in Matej Hriberšek (ur.), Nesem te v zibel drugega jezika. Zbornik ob petdesetletnici društva. Ljubljana: Društvo slovenskih književnih prevajalcev, 72-75.

ŠUČUR, Maja (2015) Dušanka Zabukovec, podnaslovna in književna prevajalka: Razlika med puško in pištolo. Dnevnik, 7. november. <https://www.dnevnik. si/1042723791>. (Dostop 6. 2. 2020.)

TRUPEJ, Janko (2014a) Cenzura profanosti pri podnaslavljanju. Maruška Agrež (ur.), Znanstveno srečanje doktorskih študentov, Ljubljana, 6. december 2013, (Zbornik Študentske sekcije Slavističnega društva Slovenije, 1). Ljubljana: Zveza društev Slavistično društvo Slovenije, 41-48. <https://zdsds.si/wp-content/uploads/2019/01/ zsds_kv_1.pdf $>$. (Dostop 14. 10. 2020.) 
TRUPEJ, Janko (2014b) Prevajanje rasističnega diskurza o temnopoltih v slovenščino. Primerjalna književnost 37 (3), 89-109. <https://ojs-gr.zrc-sazu.si/primerjalna_knjizevnost/article/view/6290/5948>. (Dostop 14. 10. 2020.)

TRUPEJ, Janko (2014c) Zaznamovanost slovenskega izrazoslovja za temnopolte. Slavistična revija 62 (4), 635-645. <https://srl.si/sql_pdf/SRL_2014_4_12.pdf > (Dostop 14. 10. 2020.)

TRUPEJ, Janko (2015) Strategije za podnaslovno prevajanje profanosti v slovenščino. Slavistična revija 63 (1), 17-28. <https://srl.si/sq1_pdf/SRL_2015_1_02.pdf >. (Dostop 14. 10. 2020.)

TRUPEJ, Janko (2017a) Strategies for Translating Racist Discourse about African-Americans into Slovenian. Babel: Revue internationale de la traduction / International Journal of Translation 63 (3), 322-342.

TRUPEJ, Janko (2017b) The Significance of Racial Terms in Sinclair Lewis's Kingsblood Royal and its Translations into German, Serbo-Croatian and Slovenian. Arbeiten aus Anglistik und Amerikanistik 42 (1), 121-139.

TRUPEJ, Janko (2019) Avoiding Offensive Language in Audio-Visual Translation: A Case Study of Subtitling from English to Slovenian. Across Languages and Cultures 20 (1), 57-77.

UDOVIČ, Boštjan/Maja BUČAR (2016) "Mirror, Mirror, on the Wall...": Slovenian Development Assistance in the Western Balkan Countries and its Reputation in the Region. Teorija in praksa 53 (5), 1064-1078, 1273. <https://www.fdv.uni-lj.si/docs/ default-source/tip/udovic_bucar.pdf?sfvrsn=2>. (Dostop 6. 2. 2020.)

VAN LEUVEN-ZWART, Kitty (1989) Translation and Original: Similarities and Dissimilarities, I. Target 1 (2), 151-181.

VAN LEUVEN-ZWART, Kitty (1990) Translation and Original: Similarities and Dissimilarities, II. Target 2 (1), 69-95.

VIDOVIČ MUHA, Ada (2013) Slovensko leksikalno pomenoslovje (druga, dopolnjena izdaja). Ljubljana: Znanstvena založba Filozofske fakultete Univerze v Ljubljani.

WAJNRYB, Ruth (2005) Expletive Deleted: A Good look at Bad Language. New York: Free Press.

ZABUKOVEC, Dušanka (2010) Na istem bregu. Lektorsko društvo Slovenije. <http:// www.lektorsko-drustvo.si/predavanja/na-istem-bregu>. (Dostop 6. 2. 2020.)

ŽIŽEK, Slavoj (2000) Enjoy Your Nation as Yourself!. Les Back in John Solomos (ur.), Theories of Race and Racism: A Reader. London/New York: Routledge, 594-606. 


\section{POVZETEK}

Članek obravnava strategije za prevajanje profanosti v slovenskih, hrvaških in srbskih podnapisih 20 filmov, ki so posneti v angleškem jeziku. Analiza je za vsak jezik obsegala 1.862 primerov profanosti - primerjava je pokazala tako skupne značilnosti kot razlike. V slovenskih podnapisih je bilo ohranjenih 51,7 \% primerov profanosti, v drugih dveh jezikih pa je bil ta delež večji: $60,8 \% \mathrm{v}$ srbskih in $63,1 \%$ v hrvaških podnapisih. Če je bilo v istem filmu uporabljenih več primerov istega profanega izraza oz. fraze, pogosto naletimo na različne prevodne rešitve - to velja za prevajalske strategije v vseh treh jezikih. Objektivni razlogi za to, da profanost v podnapisih ni bila ohranjena, v vseh treh jezikih obstajajo v približno petini primerov (SLO: 21,0 \%; SRB: 18,8 \%; HRV: 20,5 \%), medtem ko lahko v preostalih primerih izogibanja profanosti govorimo o (samo)cenzuri. Podrobnejša kategorizacija primerov profanosti, ki niso bili ohranjeni, je pokazala, da je bila v slovenskih podnapisih strategija izpuščanja uporabljena bistveno pogosteje (33,9\%) kot v srbskih (26,9 \%) in hrvaških $(26,1 \%)$ podnapisih, razlike med pogostostjo kategorij modulacija registra (SLO: 12,0 \%; SRB: 10,9 \%; HRV: 9,3\%), radikalna sprememba pomena (SLO: 1,5\%; SRB: 1,2\%; HRV: 0,9\%) in zamenjava z zaimkom (SLO : 0,9\%; SRB: 0,2 \%; HRV: 0,6 \%) pa so manj občutne. Primeri v vsakem izmed jezikov ponazarjajo, da lahko pogosto neohranjanje profanosti v prevodu vpliva na makrostrukturno raven filma, tj. tako na razumevanje dogodkov in karakterizacijo kot tudi na percepcijo odnosov med posameznimi liki.

Ključne besede: avdiovizualno prevajanje, profanost, filmski podnapisi, premiki, cenzura

\section{ABSTRACT}

\section{A TRANSLATIONAL COMPARISON OF THE ACCEPTABILITY OF PROFANITY IN SLOVENIAN, CROATIAN AND SERBIAN FILM SUBTITLES}

This article analyses the strategies for translating profanity in the Slovenian, Croatian and Serbian subtitles of 20 English-language films. Translations of 1,862 examples of profanity from the films into each of the three languages were examined, and the results showed both common characteristics and differences. In the Slovenian subtitles, $51.7 \%$ of the profanity was preserved, while this number is higher in both the Serbian (60.8\%) and Croatian (63.1\%) subtitles. In cases where several examples of a profane term or phrase were used in the same film, these were frequently translated differently, and this is true for the translation strategies in all three languages. There were objective reasons for not preserving profanity in approximately one-fifth of all the non-preserved examples in all three languages (SLO: 21.0\%; SRB: 18.8\%; CRO: 20.5\%), while in the other cases the omissions can be attributed to (self-)censorship. A more detailed categorisation of examples of non-preserved profanity showed that in the Slovenian subtitles the strategy of deletion was used significantly more often (33.9\%) than in the Serbian (26.9\%) and Croatian (26.1\%) subtitles, while 
the differences between the categories modulation of register (SLO: 12.0\%; SRB: 10.9\%; CRO: 9.3\%), radical change of meaning (SLO: 1.5\%; SRB: 1.2\%; CRO: 0.9\%) and substitution with a pronoun (SLO: 0.9\%; SRB: 0.2\%; CRO: 0.6\%) were less significant. Examples from the subtitles in each language illustrated that where profanity is frequently not preserved in translation, this may influence the macrostructural level of a film: i.e., it may affect the viewers' understanding of events and characterisation, as well as the perception of relationships between particular characters.

Keywords: audio-visual translation, profanity, film subtitles, shifts, censorship 